\title{
Comunicação Dialógica na Articulação dos Conhecimentos Matemático, Tecnológico e Reflexivo a Partir de uma Prática de Modelagem na Educação Básica
}

\section{Dialogical Communication in the Articulation of Mathematical, Technological and Reflective Knowledge from a Modeling Practice in Basic Education}

\author{
Silvana Cocco Dalvi*a; Oscar Luiz Teixeira de Rezende ${ }^{\mathrm{b}}$, Luciano Lessa Lorenzoni ${ }^{\mathrm{a}}$ \\ ${ }^{a}$ Prefeitura Municipal de Castelo. ES, Brasil. \\ 'Instituto Federal de Educação, Ciência e Tecnologia do Espírito Santo. ES, Brasil. \\ *E-mail: silvanaej@hotmail.com
}

\begin{abstract}
Resumo
A matemática ainda se configura como argumento definitivo e inquestionável influenciando o modo de produção e a tomada de decisões das pessoas. Assim, a educação matemática deve preparar os estudantes para agirem criticamente diante das informações e resultados oriundos dos estudos matemáticos, norteados por ideologias. Nesse sentido, o presente trabalho tem por objetivo evidenciar a relevância da comunicação dialógica na articulação dos conhecimentos matemático, tecnológico e reflexivo a partir de uma atividade de modelagem matemática evidenciando a necessidade da interpretação dos modelos matemáticos. Esses conhecimentos devem integrar a educação matemática com potencial para atender as demandas da contemporaneidade. Para caracterizar o diálogo pautou-se no Modelo de Cooperação Investigativa tendo como viés o desenvolvimento de uma atividade de modelagem que consistiu na medição do consumo diário de água feito por alunos do $8^{\circ}$ ano do ensino fundamental. A pesquisa é de abordagem qualitativa cujos instrumentos usados na produção dos dados foram o diário de campo do pesquisador e dos alunos e gravações em áudio. Os resultados revelam que a comunicação dialógica é o pilar para o desenvolvimento dos conhecimentos matemático, tecnológico e reflexivo possibilitando discutir as ferramentas matemáticas, sua aplicação e impactos dos modelos matemáticos na sociedade. Nessa configuração, a modelagem matemática se mostra como uma possibilidade viável uma vez que aborda problemas da realidade dos interesses dos alunos e favorece o diálogo. Cabe salientar que o diálogo é um processo investigativo que ocorre de forma cooperativa entre professor e alunos em busca de novas aprendizagens em um ambiente escolar democrático.
\end{abstract}

Palavras-chave: Educação Matemática. Comunicação Dialógica. Modelagem. Aprendizagem

\begin{abstract}
Mathematics is still a definitive and unquestionable argument that influences people's production and decision-making. Thus, mathematics education should prepare students to act critically in the face of information and results from mathematical studies, guided by ideologies. In this sense, the present work aims to highlight the relevance of dialogical communication in the articulation of mathematical, technological and reflective knowledge from a mathematical modeling activity showing the need for the interpretation of mathematical models. This knowledge must integrate mathematical education with the potential to meet the demands of contemporary times. To characterize the dialogue, the Investigative Cooperation Model was based on the development of a modeling activity that consisted of measuring the daily water consumption made by students in the 8th grade of elementary school. The research has a qualitative approach whose instruments used in the production of the data were the researcher and students'field diary and audio recordings. The results reveal that dialogical communication is the pillar for the development of mathematical, technological and reflective knowledge, enabling the discussion of mathematical tools, their application and the impact of mathematical models on society. In this configuration, mathematical modeling is shown to be a viable possibility since it addresses problems in the reality of the students' interests and favors dialogue. It should be noted that dialogue is an investigative process that takes place cooperatively between teacher and students in search of new learning in a democratic school environment.
\end{abstract}

Keywords: Mathematical Education Dialogic communication. Modeling. Learning.

\section{Introdução}

O avanço tecnológico ocorrido ao longo dos tempos transformou a sociedade nas esferas sociais, políticas e econômicas, modificando o modo de produção e o jeito de viver do homem. O sistema educacional não é inerte a essas mudanças emergindo também, novos olhares sobre seus objetivos e metodologias, bem como a reflexão do estudante que se almeja formar.

Diante desse cenário, é pertinente ponderar sobre a educação matemática, uma vez que, segundo Skovsmose (2001) a matemática está formatando nossa sociedade exigindo uma formação crítica do aluno inserido na contemporaneidade. A matemática, como criação humana e construto social, é relevante para o desenvolvimento tecnológico, contudo, traz à tona a discussão referente a democracia.

Outro ponto relevante é o discurso da 'ideologia da certeza', que implica em considerar que a melhor solução de um problema se dá sempre por meio da matemática; acreditase que ela é totalmente confiável e pode ser aplicada a todo tipo de problema, uma vez que é possível simplificá-lo e matematizá-lo (Borba \& Skovsmose, 2001). As bases dessa ideologia fundamentam-se na confiança que se tem nos números e na crença de que a matemática é capaz de explicar, por completo, a realidade. Essa visão equivocada sugere a postura crítica dos educadores, que devem desenvolver no estudante a capacidade de interpretar as situações baseadas nos 
argumentos matemáticos. Essa é uma demanda da sociedade altamente tecnológica que se vive.

Por essa ótica é pertinente pensar a seguinte questão: a educação matemática tem partido de contextos reais, como as problemáticas ambientais e sociais, contribuindo para a formação cidadã do estudante? Esse olhar evidencia a necessidade de despertar no aluno o hábito de questionar e analisar os modelos matemático, refletir seus impactos na sociedade e sua influência na tomada de decisões das pessoas.

Surge, assim, o desafio de reconstruir a educação matemática de forma a desenvolver nos alunos aspectos democráticos, munindo-os de conhecimentos que possam ajudá-los a compreender e tomar decisões autônomas em debates sociais respaldados pela matemática. Essa perspectiva é condizente com uma concepção moderna de educação matemática que articula os seguintes conhecimentos ${ }^{1}$ : matemático, tecnológico e reflexivo, a saber:

1) Conhecimento matemático, se refere à competência normalmente entendida como habilidades matemáticas, incluindo as competências na reprodução de teoremas e provas, bem como ao domínio de uma variedade de algoritmos [...].

2) Conhecimento tecnológico, se refere às habilidades em aplicar a matemática e às competências na construção dos modelos [...]. De forma geral, é o entendimento necessário para usar uma ferramenta tecnológica para alcançar alguns objetivos tecnológicos.

3) Conhecimento reflexivo, se refere à competência de refletir sobre o uso da matemática e avaliá-lo. Reflexões têm a ver com avaliações das consequências do empreendimento tecnológico. (Skovsmos, 2013, p.116-116).

Conjugar esses três conhecimentos na prática pedagógica do professor de matemática é criar a possibilidade de uma aprendizagem mais conectada com o tempo presente. Assim, o conhecimento matemático permite dominar a linguagem, os algoritmos e as estruturas axiomáticas essenciais para o desenvolvimento do conhecimento tecnológico, que por sua vez é necessário para o desenvolvimento das tecnologias; o conhecimento reflexivo contribui para uma visão crítica dos alunos a partir dos conhecimentos tecnológicos, que por si só não são capazes de analisar os resultados de sua própria produção (Skovsmose, 2013, p.85). A construção do conhecimento reflexivo é essencial para o desenvolvimento de competências que possibilitam a atuação do sujeito em um mundo altamente complexo (Souza, Mendonça, \& Amaral, 2015).

Para exemplificar essa ideia pode-se pensar no projeto de construção de uma casa: o conhecimento matemático se faz necessário para dar sustentação ao conhecimento tecnológico de enquadrar a casa dentro do terreno e calcular as quantidades de materiais utilizados na sua construção; a reflexão para avaliar os impactos ao meio ambiente da atividade de extração de areia e de pedra, da fabricação do cimento, dos preços, entre outros. O conhecimento matemático referese as habilidades matemáticas; o conhecimento tecnológico é 'míope', não se dirige a uma autocrítica necessitando do conhecimento reflexivo, que tem como seu objeto o uso da própria matemática (Skovsmose, 2013).

Ciente da complexidade do processo educativo essa pesquisa delinei-a-se na natureza da atividade, apoiandose na modelgem matemática, e na comunicação dos atores envolvidos no processo ensino e aprendizagem, com foco na comunicação dialógica. Esses pressupostos são fundamentais na promoção de uma educação que contemple os conhecimentos matemático, tecnológico e reflexivo, essenciais para a alfabetização matemática atual.

O objetivo desse trabalho é evidenciar a relevância da comunicação dialógica na articulação dos conhecimentos matemático, tecnológico e reflexivo a partir de uma atividade de modelagem matemática, mostrando a necessidade de interpretações dos modelos matemáticos. A atividade de modelagem realizada teve como tema extraído do contexto sociocultural dos alunos a problemática da escassez de água, e consistiu na medição do consumo diário de água por alunos do $8^{\circ}$ ano do ensino fundamental de uma escola localizada em Castelo, Espírito Santo. De abordagem qualitativa, é parte de uma pesquisa de mestrado desenvolvida no Instituto Federal de Ciência e Tecnologia do Espírito Santo - IFES.

$\mathrm{Na}$ estrutura do texto apresenta-se os materiais e métodos da pesquisa. Em seguida, aborda-se o modelo de cooperação investigativa e a modelagem matemática. Na sequência, descreve-se a atividade de modelagem fazendo as discussões e apresentando os resultados sobre a temática. Por fim, as conclusões do estudo.

\section{Material e Métodos}

A pesquisa é de abordagem qualitativa pautada nos estudos de Minayo (2003, p.21-22) por considerar que esse tipo de pesquisa preocupa-se com um nível da realidade que não pode ser quantificado, de caráter essencialmente qualitativo: "Trabalha com o universo de significados, motivos, aspirações, crenças, valores e atitudes, o que corresponde a um espaço mais profundo das relações, dos processos e dos fenômenos que não podem ser reduzidos à operacionalização de variáveis". Essa realidade, no caso a sala de aula e seus agentes, constitui um ambiente rico de investigações que contribuem para o desenvolvimento da Ciência no âmbito da educação matemática, objeto em estudo.

Os instrumentos usados para a produção de dados foram o diário de campo do pesquisador. Os sujeitos da pesquisa foram alunos de uma turma do $8^{\circ}$ ano regular do ensino fundamental de uma escola municipal, localizada em Castelo, Espírito Santo. As análises buscam a compreensão dos dados confrontando a teoria com a prática, e são feitas à luz do

1 No texto original o termo utilizado é conhecer. Aqui estamos referindo ao conhecimento, ou seja, ao ato de conhecer, pois o nosso foco está na aprendizagem do aluno. 
referencial teórico que embasa a pesquisa.

\section{Modelo de cooperação investigativa - Modelo CI}

Com as novas demandas e aplicação da matemática na contemporaneidade evidencia-se a necessidade de articular os conhecimentos matemático, tecnológico e reflexivo, a educação matemática no intuito de favorecer a formação cidadã dos estudantes. Nessa perspectiva, cabe a reflexão em torno da comunicação que se estabelece nas aulas de matemática que não deve se fundamentar no monólogo expositivo de conteúdos pelo professor sem a interação com os alunos.

Nesse sentido Alro e Skovsmose (2010) afirmam que a comunicação na sala de aula interfere na qualidade da aprendizagem e, assim, deve ser entendida como uma possibilidade na qual cada perspectiva verbalizada pode ser o fio condutor para uma investigação, contribuindo na aquisição de novos conhecimentos, por parte do professor e também dos alunos. Foi pensando nessa forma de comunicação que os autores elaboraram o modelo de cooperação investigativa Modelo-CI, representado na Figura 1, reunindo oito atos da fala que favorecem a aprendizagem.

Figura 1 - O modelo de cooperação investigativa

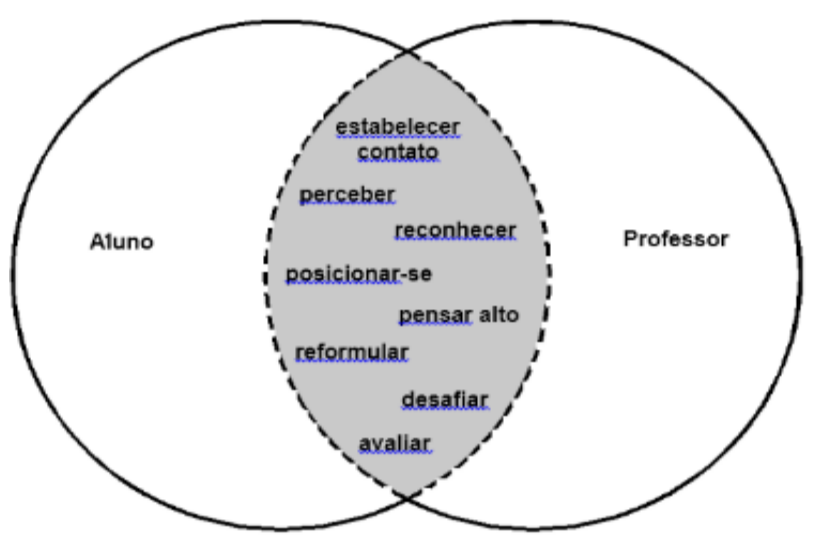

Fonte: Alro \& Skovsmose (2010, p. 69).

No esquema da Figura 1, observa-se que professor e aluno estão num mesmo nível de discurso, sem nenhuma dominação de um sobre o outro. A seguir, discrimina-se os oito atos de comunicação do Modelo- CI de acordo com Alro e Skovsmose (2010):

- Estabelecer contato é visto como uma maneira de criar uma sintonia entre os participantes prestando atenção nas perspectivas um do outro e às suas contribuições. Abrange aspectos emocionais da cooperação investigativa exigindo respeito mútuo, responsabilidade e confiança uns nos outros. Os participantes estão dispostos a realizar a investigação. Surgem expressões do tipo: "É isso?", "Certo?", "Concordam?" o que evidencia o relacionamento de parceria e integração entre os envolvidos na investigação.

- Perceber perspectivas é um processo de examinar possibilidades, criar hipótese, manter a curiosidade. Significa perceber as relações que o aluno está fazendo com o problema, mesmo sem ter certeza de sua validade. Os alunos assumem a condução do processo investigativo.
- Reconhecer a perspectiva pode ser entendida como um esforço de matematizar a situação em que as propostas poderão ser reformuladas e aprofundadas. Consiste em delinear as ideias matemáticas. Significa ser capaz de reconhecer um princípio ou algoritmo matemático que dê sentido a atividade e aos cálculos subsequentes.

- Posicionar-se está relacionado ao compartilhar o que se sabe, expressar o que pensa estando receptivo às argumentações de seu posicionamento. As declarações do tipo: "Não compreendi.", "Entendi de outra forma.”, “Certo?”, "Não acha isso?" Revelam que a comunicação está ocorrendo não na tentativa de defender um ponto de vista porque ele é pessoal, mas de torná-lo público para ser analisado e questionado se deve ser aceito ou rejeitado.

- Pensar alto significa expressar pensamentos, ideias e sentimentos permitindo que suas perspectivas sejam conhecidas por todos. É uma conversação onde os participantes examinam e descrevem seus pressupostos sobre a questão. É tornar o pensamento público.

- Reformular significa repetir o que já foi dito do seu jeito. É um parafrasear elucidando o processo argumentativo. Os participantes confirmam o entendimento de uma perspectiva comum ou eliminam dúvidas ainda existentes no processo de investigação.

- Desafiar significa tentar ver as coisas em outro sentido. Uma questão hipotética ou uma questão associada. Uma precondição para desafiar o aluno é o esclarecimento de perspectivas dando sugestões investigativas.

- Avaliar as perspectivas faz parte de todo processo investigativo e é feito por alunos e professor procurando chegar a um consenso. O objetivo não está centrado em achar a perspectiva 'correta', mas em examinar e refletir as diferentes perspectivas que surgem no diálogo. O 'certo' ou 'errado' não pode prevalecer num processo investigativo.

Uma característica fundamental do Modelo-CI é a escuta ativa onde os participantes do diálogo não absorvem passivamente as palavras que são emitidas, mas procuram entender e ajudar quem fala, fazendo perguntas, procurando compreender o que se passa com o outro. Os alunos prestam atenção às perspectivas uns dos outros examinando-as, colocando-se à disposição para contribuir com sua elucidação.

Para Alro e Skovsmose (2010) o diálogo é visto como um processo investigativo de perspectivas sendo, portanto, imprevisível. Segundo eles, as perspectivas devem ser explicitadas mantendo a curiosidade e a reflexão sobre novas indagações que podem surgir no diálogo, isto é, os alunos assumem o processo investigativo formulando e planejando a investigação de forma diversificada. Quando os atos dialógicos marcam o discurso dizemos que a comunicação foi dialógica.

Cabe ressaltar, conforme destaca Freire (1996, p.139), que o processo da comunicação não é neutro, é sempre feito em "favor ou na defesa, sutil ou explícita, de algum ideal contra algo e contra alguém, nem sempre claramente referido. Daí também o papel apurado que joga a ideologia na comunicação". Esse argumento se traduz na educação matemática que pode contribuir para a formação de estudantes submissos a grupos opressores dominantes, quando não se dá oportunidade para expressarem seus pensamentos e a aula restringe-se a transmissão de conteúdos pelo professor. Numa visão oposta, a comunicação nas aulas de matemática pode ser dialógica favorecendo a educação libertadora onde a 
realidade é discutida criticamente, os alunos são estimulados a questionarem e opinarem exercendo sua cidadania, sendo protagonistas no processo de ensino e aprendizagem.

\subsection{Modelagem matemática}

Alargando as discussões no que tange a educação matemática na atualidade é preciso se ater a natureza das atividades desenvolvidas. Nesse sentido, listas repetitivas de exercícios sempre tendo o livro-texto por base não se enquadram, confortavelmente, na proposta de articular os conhecimentos matemático, tecnológico e reflexivo, visto que, geralmente, a participação do aluno restringe-se a resolução mecanizada do problema.

Nesse contexto, Skovsmose (2014, p. 45) sugere atividades pautadas num cenário para investigação, isto é, o "terreno sobre o qual as atividades de ensino-aprendizagem acontecem". Considera que as atividades de pesquisa constituem em cenários para investigação, abertura de possibilidades, uma vez que, por natureza, remete a algum envolvimento e interesse por parte do investigador; a ideia de pesquisa e investigação traz à tona a questão da intencionalidade considerando a aprendizagem como ação. "O que importa para os alunos é realizar sua própria pesquisa e não apresentar resultados de fato" (p. 53). Eles passam a conduzir as investigações, formulando e validando suas hipóteses.

É nessa perspectiva de educação matemática que a modelagem se apresenta como uma possibilidade na superação de práticas pedagógicas que não condizem mais com as expectativas atuais. Na literatura encontra-se muitos teóricos que advogam a favor da modelagem no campo educacional como verifica-se a seguir:

Barbosa (2004) considera que se queremos construir uma sociedade democrática onde as pessoas exerçam a cidadania, elas precisam ser capazes de intervir nos debates baseados em matemática e, para isso, é necessário não apenas informar, mas educar criticamente através da modelagem. Considera que

O ambiente de Modelagem está associado à problematização e investigação. O primeiro refere-se ao ato de criar perguntas e/ou problemas enquanto que o segundo, à busca, seleção, organização e manipulação de informações e reflexão sobre elas. Ambas atividades não são separadas, mas articuladas no processo de envolvimento dos alunos para abordar a atividade proposta. Nela, podem-se levantar questões e realizar investigações que atingem o âmbito do conhecimento reflexivo (Barbosa, 2004, p.75).

Nesse ambiente de modelagem, dois pontos são cruciais: a problematização que deve ter referência num contexto real - os temas para estudo devem ser extraídos do contexto sociocultural dos alunos e devem constituir-se, realmente, em um problema para eles; o outro é a investigação que implica em não possuir esquemas prévios para abordar o problema os procedimentos não são fixados de antemão, só os conhecem à medida em que os alunos usam sua autonomia e investigam um possível caminho para solucionar o problema, o que exige deles um determinado esforço intelectual (Barbosa, 2004).

$\mathrm{O}$ autor destaca que num ambiente de modelagem a sala de aula é vista como um espaço discursivo de muitas vozes, e toma a noção de rotas de modelagem no sentido da ação do discurso dos alunos na construção do modelo matemático referente à situação-problema em estudo. Ele definiu três formas de discussões a saber:

As discussões matemáticas referem-se aos conceitos e às ideias integralmente pertencentes à disciplina matemática. As discussões técnicas, ao processo de matematização da situação em estudo. E, por sua vez, as discussões reflexivas referem-se à conexão entre os pressupostos utilizados na construção do modelo matemático e os resultados, bem como à utilização desses últimos na sociedade (Barbosa, 2007, p.165).

Nota-se que o autor faz uma alusão aos conhecimentos matemático, tecnológico e reflexivo, o que clarifica a necessidade de uma comunicação dialógica. A natureza da atividade matemática deve propiciar essas discussões e o professor deve estar aberto as indagações dos alunos além de fomentar, no cotidiano da sala de aula, as discussões matemáticas, técnicas e reflexivas.

Outro ponto relevante é apontado por Klüber (2016) ao considerar que na modelagem matemática educando e educador são sujeitos ativos do processo de ensino e aprendizagem matemática. Ele destaca que ela é uma facilitadora da construção do conhecimento e de conceitos matemáticos que emergem durante seu desenvolvimento. Considera que a modelagem favorece direcionamentos diferentes das formas usuais de ensinar matemática, visto que seu encaminhamento se dá por meio da interação, cooperação e colaboração entre professor e aluno.

Dalvi, Rezende, Boone e Lorenzoni (2020, p. 63) também destacam a importância da comunicação numa prática de modelagem que deve ser marcada pelos elementos contidos no "[...] Modelo- CI, na escuta ativa e na disposição do professor e dos alunos para investigarem as perspectivas imprevisíveis que emergem no diálogo. É uma relação de reciprocidade em busca do conhecimento onde os pontos de vistas são expostos e ouvidos de forma democrática". Consideram, ainda, que o diálogo na atividade de modelagem possibilita ao professor descobrir os interesses dos alunos, a visão que têm do mundo e dos problemas socioculturais em que estão inseridos, conectando suas realidades ao estudo da matemática no ambiente escolar.

\section{Descrição da Atividade de Modelagem, Resultados e Discussões}

O tema da atividade de modelagem surgiu quando os alunos relataram a preocupação com a escassez de água no município de Castelo. O rio que passa pela cidade estava quase seco e a companhia de abastecimento de água passava o "carro de som" nas ruas esclarecendo sobre a importância de não desperdiçar água, além de informar sobre seu racionamento. Esse contexto despertou o interesse dos alunos 
que não estavam habituados a falta de água.

Conforme destaca Barbosa (2004) o tema para uma atividade de modelagem deve partir do contexto sociocultural dos alunos e se constituir um problema para eles. Essas características estão presentes na atividade de modelagem uma vez que, Castelo está localizado no interior, ao Sul do Espírito Santo, onde a água sempre foi abundante. No entanto, no final de 2015 o município atravessou um longo período de estiagem que refletiu na rotina dos castelenses se tornando um problema significativo para eles, pois se depararam com a insuficiência de água. É nesse cenário que foi desenvolvida a atividade de modelagem matemática.

A partir dessa problemática foi exibido e discutido a reportagem": "Água, planeta em crise", que falava da crise hídrica pelo mundo, inclusive no Brasil, e algumas medidas tomadas pelo governo em torno da questão. As discussões levaram os alunos a relatarem sua relação direta com o uso da água, conforme observa-se na Interação 1 a seguir. $O$ professor foi representado pela letra "P", os alunos pela letra "A" seguida de um número e "G" as falas do grupo quando não foi possível identificar uma única fala.

Interação 1 - Os alunos falam da sua relação com o problema em estudo

A14: A gente 'tá com água e não estamos nem aí para os que não têm.

P: Nós não estamos nem aí para o que está acontecendo. É isso?

A05: É.

A12: A gente gasta...

A09: A gente não se preocupa enquanto a gente tem aqui. A gente só se preocupa quando a gente não tiver. Entendeu? A12: Só quando chegar o nosso dia...

A18: Quando a gente tem a água, a gente não se preocupa.

A07: E, quando a gente não tem água...

A15: A gente sabe que ela está acabando, mas a gente não se preocupa.

A16: A gente sabe que vamos ficar sem água!

A14: Que, quando a gente tem água, a gente não 'tá' ligando pra quem não tem, né? A gente 'tá' usando do jeito que a gente quer!

$\mathrm{Na}$ Interação 1, já se identifica os atos dialógicos de estabelecer contato nos discursos dos alunos que se apoiam, reciprocamente, na perspectiva levantada por A14. Essa perspectiva é percebida pelos demais alunos participantes do diálogo que, se aproximam e insistem nesse assunto, examinando-a, levando-os a reconhecer que, enquanto eles têm água, gastam à vontade, sem se preocuparem em economizála, mas que um dia pode faltar. Os posicionamentos desses alunos indicam que estão a favor da ideia expressa por A14. O pensar alto dos alunos os levam a olharem para dentro de si, para as próprias ações usando a água, como fica evidenciado no discurso de A12: "A gente gasta...".

A comunicação dialógica estabelecida na aula diz respeito a escassez de água numa visão da vida em sociedade, aspecto importante num trabalho matemático que se preocupa em desenvolver a cidadania nos alunos. O professor procura investigar a visão deles em relação ao tema, o que pensam sobre a situação em estudo (Dalvi et al. 2020). É com base nessas informações que é feito o convite para medirem o seu consumo diário de água, desafiando-os com a seguinte questão: Eu sou gastão de água?

Conforme destaca Skovsmose (2014) o aluno é convidado a participar de um cenário para investigação, mas não pode ser obrigado. Esse momento em que é proposto aos alunos a medição do consumo de água é um processo relacional, do qual depende dos alunos aceitarem ou não a condução da investigação. Por isso, um cenário investigativo não é construído na autoridade de um sobre o outro, mas pelo diálogo.

A natureza da atividade proposta é aberta, isto é, cada aluno terá um resultado para a sua medição do consumo de água a partir, inclusive, das diferentes estratégias que podem ser adotadas para tal medição. O problema admite várias respostas. Os alunos decidem, mesmo que colaborativamente, como farão essa investigação e nesse percurso o diálogo ajuda a descobrir os caminhos.

Inicialmente os alunos ficaram pensativos de como realizariam as medições, mas logo começaram a trocar informações, levantar hipóteses, discutir alternativas e as ideias foram emergindo através da comunicação dialógica. Segundo Alro e Skovsmose (2010) o diálogo é um processo investigativo de perspectivas e para que aconteça é necessário o envolvimento dos alunos. Outras condições são estabelecidas por Barbosa (2004) quando explica que na modelagem o tema deve ter referência num contexto real e não se deve conhecer a priori os esquemas de resolução. Ou seja, nenhuma estratégia de medição foi imposta pelo professor deixando os alunos livres para decidirem qual caminho achavam mais viável, o que exigiu deles esforço intelectual.

Após as medições os alunos apresentaram suas estratégias e resultados que foram bem dinâmicos e variados. Tomaremos para análise o modelo matemático construído por A15, representado na Figura 2.

Figura 2 - Procedimento de medição do aprendiz A15 usando a conta de água

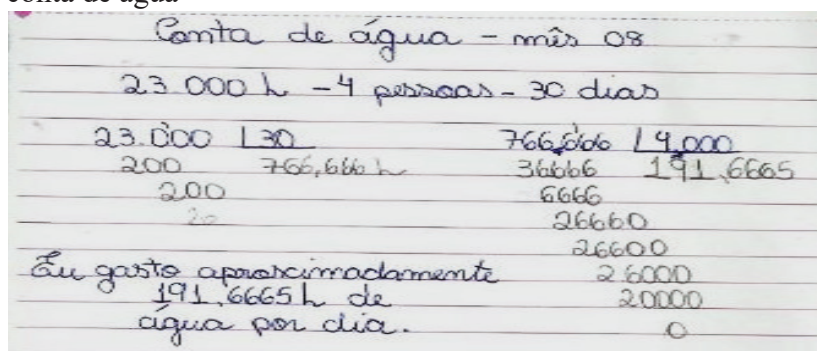

Fonte - Diário de campo de A15.

Observa-se que A15 usou a conta de água de sua casa para resolver o problema. Transformou 23 de água em 23 
000 litros; em seguida dividiu esse consumo mensal por 30 dias para encontrar o consumo diário resultando em 766, 666 litros; dividiu pelo total de pessoas de sua casa, no caso 4 , e obteve aproximadamente um consumo diário de 191,6665 litros de água.

A seguir descreve-se a Interação 2 após A15 ter exposto para a turma como procedeu para fazer a medição.

Interação 2: Discussões do processo de medição do consumo diário de água feito por A15

P: Tá. Alguém mais usou a conta de água?

A15: [...] eu acho que o meu está errado. De todo mundo está dando mais de 200 litros e o meu deu 190 litros e poucos.

P: Turma o que vocês acham da estratégia utilizada por A15? A03: O dela é uma média e não o que cada um gasta. Não é o consumo de cada um.

A10: Cada pessoa não gasta a mesma quantidade de água, então, na conta vai tá uma coisa de todo mundo, da família. Não vai conseguir saber o de cada um.

Os alunos A03 e A10 refletem sobre a solução de A15 e a aplicabilidade do uso da média aritmética para resolver o problema concluindo que não foi a estratégia mais indicada. Os atos dialógicos estão presentes na comunicação no sentido de elucidar uma perspectiva reconhecida pela turma. O estabelecer contato acontece quando A15 presta atenção nas perspectivas socializadas pelos alunos e reflete sobre o encaminhamento que deu para a investigação e na escuta ativa dos alunos A03 e A10. Esses alunos percebem a perspectiva usada por A15 reconhecendo- $a$ e procuram examinar a ideia matemática que foi verbalizada se posicionando, apresentando argumentos que ajudam A15 a esclarecer sua dúvida. Os alunos ao pensarem alto expressam suas ideias, examinam e desenvolvem os pressupostos de como estão entendendo a questão. A avaliação acontece na própria autoanálise de A15 e no apoio construtivo dado por A03 e A10.

Observa-se que os alunos adotam uma postura de investigadores, coletando os dados, organizando as informações e debatendo os procedimentos e resultados. No centro da atividade de modelagem está a pesquisa, ou seja, o aluno está aprendendo a ser um pesquisador. É nesse sentido que Skovsmose (2014) explica que o importante é que os alunos realizem a investigação, e não os resultados que são de fato apresentados. Ao discutir coletivamente a pesquisa de A15 que usou a conta de água, os próprios alunos descobrem que esse procedimento não foi adequado ao problema proposto, o que implica também na apresentação do resultado do consumo de água. Cabe salientar, portanto, que a aprendizagem nesse contexto não está padronizada no certo ou errado, mas na pesquisa que o aluno desenvolve frente à realidade e ao problema que deve ser resolvido.

As interações 1 e 2 acontecem num clima harmonioso no qual as perspectivas levantadas pelos alunos são examinadas, discutidas e socializadas, constituindo fontes de novas aprendizagens. O professor age em conjunto com os alunos, atento a cada etapa e direcionamento que a modelagem toma, reconhecendo suas perspectivas, o jeito como entendem o problema, dando-lhes oportunidades para expressarem seus pensamentos. Professor e alunos estão envolvidos no processo de investigação com a finalidade de responderem a indagação: Eu sou gastão de água?

Concluídas as apresentações e debates dos procedimentos e resultados do consumo de água, o professor estimula a reflexão sobre a construção dos modelos matemáticos, conforme apresentado na Interação 3.

Interação 3: Reflexão sobre a construção dos modelos matemáticos usados na medição do consumo diário individual de água

P: Parabéns gente. Muito bom! Agora vamos pensar um pouco nas variáveis que vocês usaram. Quero dizer, realmente vocês colocaram todas as ações diárias que usaram a água?

G: Sim. (convictos)

P: Pensa bem gente! Vocês se lembraram de todas as ações que precisam da água para calcular o consumo dela? (Silêncio do grupo por alguns instantes)

A17: Bem professora, se for para considerar as coisas da casa eu não coloquei a faxina que tem que lavar a varanda lá de casa.

P: Então, se não limpar a casa com a água você vai adoecer na sujeira né?!

A5: Eu não considerei a lavagem da roupa na máquina.

P: Está vendo! Mais alguém?

A9: Ixi! E eu não coloquei a água que gasta para lavar as vasilhas que eu uso, como o copo, prato, garfo...

P: E se vocês incluíssem isso agora? O consumo de vocês iria mudar.

G: Claro, sim.

P: Vocês já pararam para pensar que ao resolvermos um problema, por mais que a gente queira, pode ficar alguma coisa (variável) que não vai ser contemplada?

A7: É isso professora! Minha mãe tem um salão e ela precisa calcular tudo para saber o preço. Assim ó: o aluguel que ela paga, a energia que gasta, a moça que trabalha lá, o prejuízo que tem de algumas freguesas que não pagam, por exemplo, o penteado do cabelo, e se ela não fizer certinho, tentar colocar tudo pode ficar no prejuízo e ter que fechar o salão.

A interação 3 revela que a ideologia da certeza, (Borba \& Skovsmose, 2001) continua presente na realidade dos alunos, na crença da superioridade da matemática como verdade suprema. O silêncio da turma é um indicativo que não está acostumada a questionar modelos matemáticos. É com a mediação do professor que A17, A5 e A9 descobrem que não consideram o uso da água em situações relevantes de seu consumo e a inserção dessas variáveis afetariam o resultado final do modelo matemático.

A discussão fez com que os alunos pensassem como um modelo matemático é construído. A perspectiva de A7 demostra sua compreensão em torno da discussão que extrapola a investigação feita através da modelagem. Ele reconhce a presença da matemática no trabalho da mãe e como as variáveis interferem em sua tomada de decisão, no caso, o preço do serviço no salão de beleza. Esse contexto retrata o potencial da modelagem matemática em explorar o cotidiano dos alunos possibilitando a articulação entre os conhecimentos matemático, tecnológico e reflexivo.

No término da atividade os alunos descobriram que gastavam mais água que imaginavam, como pode ser observado 
na produção textual de A06, na Figura 3.

Figura 3- Reflexão do consumo de água feito por A06

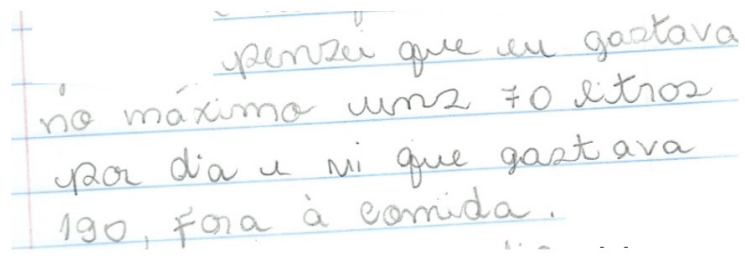

Fonte: Diário de campo de A06.

A atividade de modelagem permitiu que A06 descobrisse a visão equivocada de sua realidade ao constatar que gastou 190 litros de água sem considerar seu uso na preparação da comida. Para isso, A06 aplicou as ferramentas matemáticas para fazer a medição do consumo diário de água, mas não ficou nisso. Ele foi capaz de analisar o resultado que foi significativo, pois 190 litros de água representava um consumo alto em vista de sua previsão que era de 70 litros. Esse confronto com a realidade é um exemplo de como a modelagem pode levar o aluno a um novo olhar sobre seus hábitos, sua relação consigo mesmo e com o mundo ao seu redor.

Nota-se que no decorrer da atividade de modelagem os alunos fizeram discussões matemáticas, técnicas e reflexivas, (Barbosa, 2007) aplicando as ferramentas matemáticas na resolução da problemática: Eu sou gastão de água? De forma reflexiva argumentaram o uso da média aritmética usada por A15 e as variáveis não contempladas nos modelos construídos (Interação 3). Esse direcionamento dado a educação matemática supera a mecanização de conteúdos dissociados do contexto da realidade sociocultural dos alunos.

Dalvi, Rezende e Lorenzoni (2017) explicam que numa atividade de Modelagem Matemática, o conhecer tecnológico utiliza-se do conhecer matemático e outros para a construção de um modelo que represente o problema em questão, sem, no entanto, trazer à luz uma postura reflexiva de seus impactos. O conhecer reflexivo, ao se apoiar nos conhecimentos matemático e tecnológico, possibilita aos alunos avaliarem os impactos de suas escolhas no modelo matemático e essa relação com a realidade. Esses conheceres se fizeram presente na prática de modelagem, quando por exemplo, A15 utilizase do algoritmo da divisão, conhecimento matemático, aplicando-o em seu modelo para descobrir seu consumo de água, isto é, o conhecimento tecnológico, e os argumentos de A03 e A10 ao constatarem que o uso da média não forneceu o consumo individual de A15, no caso, o conhecimento reflexivo.

Cabe salientar que o conhecimento reflexivo nem sempre acontece de forma espontânea, sendo necessário, o estímulo e a criticidade do professor em promovê-lo. Esse contexto é evidenciado na Interação 3 quando os alunos, num primeiro momento, afirmam a veracidade e completude de seus modelos e, num segundo momento, ficam em silêncio, pensativos em quais variáveis não teriam incluídos, demonstrando não estarem habituados a questionarem resultados matemáticos.
É importante destacar que a comunicação dialógica apoiada no Modelo-CI acompanhou todo o processo de modelagem: a escolha do tema, o momento de abertura de possibilidades quando os alunos aceitaram investigar a problemática, a apresentação dos procedimentos e resultados da medição fazendo a matematização do problema, as reflexões dos modelos construídos e a finalização, ao considerarem que eram gastões de água.

Conforme destaca Klüber (2016) a modelagem matemática se dá por meio das interações, cooperação e colaboração entre professor e aluno, ambos sujeitos ativos do processo de ensino e aprendizagem. No encaminhamento dado a modelagem, nota-se que o professor faz a mediação de forma dialogada estimulando os alunos a verbalizarem suas perspectivas, desafia-os a pensarem a realidade no contexto da escassez de água, a compreenderem a necessidade planetária em usar a água de forma racional. Educando e educador estão juntos, discutindo um problema ambiental mundial: a escassez de água.

A educação matemática discutida nesse trabalho dá ênfase a comunicação dialógica no intuito de formar um estudante crítico, que diante da informação que lhe é apresentada é capaz de refletir e se posicionar com autonomia. Cabe ressaltar, a apreciação de Freire (1996) quando se refere ao jogo ideológico na comunicação das mensagens na mídia, nos noticiários e propagandas comerciais, exigindo de nossa mente um estado permanente de alerta. Ao articular os conhecimentos matemático, tecnológico e reflexivo considera-se que a alfabetização matemática está favorecendo esse despertar, não somente em relação a aplicação e impactos sociais dos modelos matemáticos, mas a qualquer informação que deve ser contextualizada e interpretada. Nesse processo a mediação do professor é essencial, pois não basta ter acesso a informação, é preciso discuti-la no seu espectro ideológico. Esse contexto revela a importância do diálogo na sala de aula.

As discussões revelam que é preciso ter clareza do que venha a ser o diálogo na educação matemática, pois é preciso estar aberto às novas perspectivas que podem mudar o rumo da investigação. Sem ele, a articulação dos conhecimentos matemático, tecnológico e reflexivo fica deficitária, uma vez que não se conhece os processos cognitivos dos alunos e suas perspectivas em relação a problemática em estudo. Formar cidadãos críticos, por meio da educação matemática, requer considerar também, a qualidade na comunicação entre professor e alunos como fator que interfere na aquisição de novas aprendizagens, e na articulação entre os conhecimentos matemático, tecnológico e reflexivo.

\section{Considerações Finais}

A educação matemática ao alcance do tempo atual é aquela que consegue articular os conhecimentos matemático, tecnológico e reflexivo rompendo a concepção axiomática e utilitarista da matemática. Busca-se por uma educação que aproxime a realidade aos conteúdos matemáticos escolares, 
colocando o aluno como protagonista do processo ensino e aprendizagem.

A educação matemática deve contribuir na formação crítica do estudante preparando-o para enfrentar com autonomia as situações formatadas pela matemática. Ela deve refletir sobre os modelos matemáticos que são ideológicos, e necessitam, portanto, de questionamentos quanto a seus impactos no ambiente e na sociedade.

Nessa vertente dois pontos são cruciais: a comunicação estabelecida na sala de aula e a natureza da atividade matemática. Esses aspectos do fenômeno educativo estão relacionados e influenciam o processo de ensino e aprendizagem. Assim, a atividade de matemática deve envolver algum problema da realidade, que discutido de forma dialógica, integre os conhecimentos matemático, tecnológico e reflexivo.

No que tange a comunicação ela deve ser marcada pelo diálogo, entendido como abertura de possibilidades e investigação. O diálogo fica travado quando professor e aluno não se abrem ao novo estando dispostos a investigarem outros caminhos para a resolução de um problema. Outro obstáculo à comunicação dialógica é a perpetuação da crença na superioridade do professor como o detentor do saber e o aluno visto como o receptor desse conhecimento por ele transmitido. Pode-se ainda destacar a falta de mediação do professor na elucidação de perspectivas em que o aluno encontra dificuldades para avançar em suas descobertas e pesquisa. $\mathrm{O}$ diálogo exige de ambos, professor e aluno, desprendimento e compromisso com a aprendizagem.

Em relação a natureza da atividade pedagógica o estudo evidencia a modelagem matemática por possibilitar desenvolver os conhecimentos matemático, tecnológico e reflexivo no decorrer de sua prática. Atividades fechadas no qual não existe a participação do aluno, cuja resposta é única, dificulta a articulação entre esses conhecimentos. Nesse sentido, o aluno assume a postura de passividade em relação a construção do conhecimento, visto que os procedimentos e respostas já foram fixados de antemão e são conhecidos do professor, cabendo-lhe, apenas a reprodução desse saber.

Nota-se que o diálogo apoiou as discussões sobre os procedimentos adotados pelos alunos para fazerem as medições do consumo diário de água. Como esses procedimentos não foram definidos a priori, os atos dialógicos do Modelo-CI permitiram a troca de experiências e conhecimentos entre os alunos, auxiliando-os na escolha das ferramentas matemáticas a serem aplicadas para solucionar o problema.

Verifica-se na atividade de modelagem desenvolvida que, a partir do diálogo, foi possível evidenciar o conhecimento tecnológico, quando os alunos utilizaram diversas estratégias para responder a questão: “Eu sou gastão de água?”; o reflexivo quando analisaram os impactos de suas escolhas, por exemplo, ao julgarem, que a média não seria a estratégia mais adequada para responder a questão; e o conhecimento matemático quando os alunos explicaram os cálculos utilizados.
A natureza dialógica do conhecimento reflexivo auxiliou os alunos a refletirem criticamente sobre o conhecimento tecnológico aplicado na prática da modelagem, bem como em outros contextos do cotidiano dos alunos, no caso, a prestação do serviço no salão de beleza, como ficou evidenciado na Interação 3. O diálogo construído como processo investigativo e autônomo no desenvolvimento da modelagem permitiu que professor e alunos examinassem novas perspectivas que emergiram durante os discursos, favorecendo o conhecimento reflexivo.

As reflexões desse trabalho se tangenciam na comunicação dialógica como referência na educação matemática, articulando os conhecimentos matemático, tecnológico e reflexivo, a partir da prática da modelagem. Esses referenciais se interligam na complexidade do fenômeno educativo e as discussões aqui apresentadas não se esgotam. Embora falase da importância do diálogo na aprendizagem é preciso ter clareza e evidenciar os tipos de discursos que o caracteriza, e a natureza da atividade pedagógica que possibilita o seu desenvolvimento. Nesse cenário, muitas outras discussões e contextos podem enriquecer e contribuir com novos conhecimentos em torno dessa temática.

\section{Referências}

Alro, H. \& Skovsmose, O. (2010). Diálogo e aprendizagem em educação matemática. Belo Horizonte - MG: Autêntica.

Barbosa, J.C. (2007). A prática dos alunos no ambiente de Modelagem Matemática: o esboço de um framework. In. J. C.Barbosa, A.D. Caldeira \& J. de L. Araújo (Orgs.), Modelagem Matemática na Educação Matemática Brasileira: pesquisas e práticas educacionais (pp.161-176). Recife: SBEM.

Barbosa, J.C. (2004). Modelagem Matemática: O que é? Por que? Como? Veritati, 2 (4), 73-80.

Borba, M. C. \& Skovsmose, O (2001). A ideologia da certeza em educação matemática. In: O. Skovsmose (Org.). Educação matemática crítica: A questão da democracia (p.127-148). Campinas: Papirus.

Dalvi, S. C, Rezende, O. L. T., Boone, M. K. S. \& Lorenzoni, L. L. (2020). Reflexões acerca da importância do diálogo na escolha do tema para uma atividade de modelagem matemática. In: Editora Poisson (Org.). Matemática, Tecnologia, Engenharia (pp. 57-64), Editora Poisson, v.35, Belo Horizonte - MG: Poisson.

Dalvi, S. C., Rezende, O. L. T. \& Lorenzoni, L. L. (2017). Aproximando pressupostos teóricos que contribuem para o desenvolvimento dos conhecimentos matemático, tecnológico e reflexivo. In. Anais da Conferência nacional sobre modelagem na educação matemática, 2017, MaringáParaná

Freire, P. (1996). Pedagogia da autonomia. São Paulo: Paz e Terra.

Klüber, T. E. (2016) Modelagem Matemática: Revisitando aspectos que justificam a sua utilização no ensino. In: C.F. Brandt, D. BURAK \& T. E. Klüber, T. E. (Org.). Modelagem matemática: perspectivas, experiências, reflexões $e$ teorizações (p.41-58). Ponta Grossa: Editora.

Minayo, M. C. de S. (Org.), Deslandes, S.F, Neto, O. C \& Gomes, 
R. (2003). Pesquisa social: teoria, método e criatividade. Petrópolis: Vozes.

SKovsmose, O. (2014). Um convite a educação matemática crítica. Campinas: Papirus.

Skovsmose, O. (2001) Educação Matematica Crítica: A questão da democracia. Campinas: Papirus.

Souza J. F. de, Mendonça, L. O. \& Amaral, L.H. (2015). Desenvolvendo competências para lidar com as finanças pessoais: contribuições de um ambiente de modelagem matemática. Rev Ensino Ciênc. Matemát., 8, (2) 142-147. Doi: https://doi.org/10.26843/rencima.v6i2.989. 